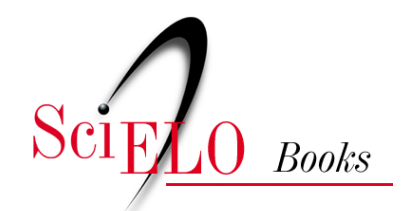

\title{
A instrução nas alagoas no período colonial os manuscritos e os primeiros vestígios de uma educação não dirigida por religiosos
}

\author{
Ivanildo Gomes dos Santos \\ Mauricéia Ananias
}

\section{SciELO Books / SciELO Livros / SciELO Libros}

SANTOS, I.G., and ANANIAS, M. A instrução nas alagoas no período colonial: os manuscritos e os primeiros vestígios de uma educação não dirigida por religiosos. In: SILVA, E.O.C., SANTOS, I.G. and ALBUQUERQUE, S.L., orgs. A história da educação em manuscritos, periódicos e compêndios do XIX e XX [online]. Rio de Janeiro: EdUERJ, 2018, pp. 25-47. ISBN 978-85-7511-483-4.

https://doi.org/10.7476/9788575114834.0003.

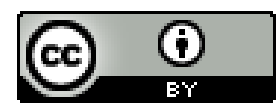

All the contents of this work, except where otherwise noted, is licensed under a Creative Commons Attribution 4.0 International license.

Todo o conteúdo deste trabalho, exceto quando houver ressalva, é publicado sob a licença Creative Commons Atribição 4.0.

Todo el contenido de esta obra, excepto donde se indique lo contrario, está bajo licencia de la licencia $\underline{\text { Creative Commons }}$ Reconocimento 4.0. 


\title{
A INSTRUÇÃO NAS ALAGOAS NO PERÍODO COLONIAL
}

\section{Os manuscritos e os primeiros vestígios de uma educação não dirigida por religiosos}

\author{
Ivanildo Gomes dos Santos \\ Mauricéia Ananias
}

\section{Introdução}

A história, e consequentemente a história da educação, é (re) construída a partir dos vestígios preservados, pois é justamente da relação do historiador com as suas fontes que se constrói o conhecimento histórico. Estas são matérias-primas indispensáveis para a reconstituição do passado e, portanto, para a operação historiográfica. Assim, para o desenvolvimento de suas pesquisas, o historiador recorre aos arquivos onde estão salvaguardados e preservados os testemunhos do passado, afinal “[...] 'ir aos Arquivos' é uma lei tácita da história [...]” (Certeau, 1982, p. 85) porque dele ficamos à mercê para as nossas ponderações. Desse modo, a busca e a localização das fontes nos arquivos, as técnicas de (re)copiar e transcrever ou fotografar os documentos utilizados fazem parte do conjunto de práticas e técnicas do ofício próprio do historiador e do historiador da educação.

A relação entre os historiadores e as fontes, sobretudo documentais, sempre foi um tanto controversa. Atualmente, o conceito 
de fonte histórica mais aceito é aquele desenvolvido e já bastante discutido pela nova historiografia. Este evidencia que qualquer traço ou vestígio deixado pelas sociedades passadas são fontes para o conhecimento histórico. De acordo com Bloch (2001, p. 79), “[...] a diversidade dos testemunhos históricos é quase infinita. Tudo que o homem diz ou escreve, tudo que fabrica, tudo que toca pode e deve informar sobre ele [...]".

Nesse sentido, o trabalho com as fontes documentais, notadamente as manuscritas, requer do pesquisador algumas noções básicas sobre organização de arquivos, leitura paleográfica e crítica das fontes, conhecimentos que nem sempre são oferecidos pelos cursos de História, e que são aprendidas no dia a dia do fazer historiográfico (Bacellar, 2014).

Salientamos que a busca incessante por documentos nos arquivos não constitui por si só uma pesquisa de grande porte, tendo em vista o risco de cair na simples descrição, ainda que esta possa ser rica em anunciar novos objetos, temas e problemas. Sendo assim, após a etapa de localização e seleção das fontes, faz-se necessário desenvolver a análise, depuração e valorização do seu conteúdo, bem como buscar confrontar os diversos dados apresentados (cruzamento de fontes). Além disso, a triagem de fontes, muitas vezes, já foi feita por aqueles que as produziram, pelos que as conservaram ou destruíram, de forma intencional ou não, e mesmo por aquelas que não resistiram ao poder do tempo.

$\mathrm{Na}$ sequência, faz-se necessário (re)interpretá-las. Essa fase certamente não é o momento mais fácil da pesquisa, pois, conforme alerta Cardoso e Vainfas (1997, p. 377), o exercício da interpretação é extremamente difícil, sobretudo “[...] no caso de pesquisas voltadas para a história das ideias, do pensamento político, das mentalidades e da cultura [...]”. Por isso, é imprescindível interrogar as fontes, fazer os documentos nos indicarem os problemas, afinal, “[...] mesmo os aparentemente mais claros 
e complacentes, não falam senão quando sabemos interrogá-los [...]" (Bloch, 2001, p. 79).

Ainda conforme o autor:

A partir do momento em que não nos resignamos mais a registrar [pura e] simplesmente as palavras de nossas testemunhas, a partir do momento em que tencionamos fazê-las falar [mesmo a contragosto], mais do que nunca impõe-se um questionário. Esta é, com efeito, a primeira necessidade de qualquer pesquisa histórica bem conduzida (Bloch, 2001, p. 75).

Tais questões ajudaram a alargar o entendimento sobre os documentos acessados, tornando-os mais generosos com relação às informações necessárias para o estudo, captando seus sentidos e revelações e podendo ser pródigos a depender do capital cultural do pesquisador e de sua capacidade de associações, confrontações e conjecturas. De acordo com Lara (2008, pp. 18-9), os historiadores precisam "inventar as fontes".

Conforme as perguntas que lhes são feitas, os documentos que sobreviveram até hoje podem se mostrar mais ou menos generosos. Claro está que não se pode fazer qualquer pergunta aos textos que encontramos nos arquivos. Quando queremos saber coisas que não estão explicitamente registradas por eles, ou que não estão ligadas às motivações que deram origem aos escritos, temos que recorrer a estratégias para obter informações - inventar modos e meios de retirar dados e obter respostas para nossas perguntas - e, portanto, inventar fontes.

Colocados em tais termos, o presente texto busca evidenciar a educação nas Alagoas no período colonial, dando destaque às pri- 
meiras iniciativas de ensino não dirigido por religiosos nas Alagoas no final do século XVIII e início do século XIX. As principais fontes utilizadas foram os manuscritos produzidos no período e que estão sob guarda do Arquivo Histórico Ultramarino de Lisboa, aos quais tivemos acesso a partir do projeto Resgate de Documentação Histórica Barão do Rio Brancoํ.

\section{A formação histórica das Alagoas e a educação religiosa nos primeiros séculos}

Comumente, as histórias das Alagoas, sobretudo aquelas que se reportam ao seu desenvolvimento histórico, são unânimes em apontar a região como de civilização da monocultura da cana-de-açúcar, marcada pela tríade: latifúndio, escravidão e patriarcalismo. Foi no "derredor" do açúcar que se desenvolveu a vida sociocultural, política, histórica e religiosa de Alagoas. Todas as áreas estavam interrelacionadas numa dinâmica configuracional, influenciando e sendo influenciadas mutuamente umas às outras. Desta feita, o povo das terras ao sul de Pernambuco teve sua identidade, cultura, costumes, hábitos e tradições atravessadas pelo engenho.

Em $O$ bangüê nas Alagoas, Manoel Diégues Junior (2006)² destaca a importância da paisagem natural, sobretudo das la-

1 O projeto Resgate de Documentação Histórica Barão do Rio Branco (Projeto Resgate) foi criado institucionalmente em 1995 por meio de protocolo assinado entre as autoridades portuguesas e brasileiras no âmbito da Comissão Bilateral Luso-Brasileira de Salvaguarda e Divulgação do Patrimônio Documental (COLUSO). Tem como objetivo principal disponibilizar documentos históricos relativos à História do Brasil existentes em arquivos de outros países, sobretudo Portugal e demais países europeus com os quais tivemos uma história colonial imbricada. Para maiores detalhes, acessar: http://www. cmd.unb.br/resgate_index.php.

2 O primeiro exemplar da obra foi lançado em 1949. Aqui, usamos a 3..$^{\mathrm{a}}$ edição, publicada em 2006, pela Editora da Universidade Federal de Alagoas - EDUFAL, tendo em vista o esgotamento da original e das versóes anteriores. 
goas, rios e riachos, para a implantação dos primeiros engenhos banguês e, consequentemente, a formação histórica das Alagoas. Esse "acidente hidrográfico" da região foi o melhor colaborador para o desenvolvimento econômico, especialmente da cultura da cana-de-açúcar. Ela, a água, fecundava o solo, dava força motriz para as moendas, auxiliava no escoamento da produção, matava a sede, bem como era importante no banho de pessoas e animais.

A colonização, levada a cabo pela união Igreja-Estado, das partes sul da capitania de Pernambuco, território que em 1817 iria emancipar-se, passando a ser chamada de Capitania das Alagoas, deu-se a partir de três principais núcleos de povoamento: ao norte, com a Vila de Porto Calvo; ao centro, com a Vila das Alagoas, atual cidade de Marechal Deodoro; e, ao sul, com a Vila do Penedo. Outro núcleo importante irá surgir com a criação da Vila de Atalaia, após a destruição do Quilombo dos Palmares, no final do século XVII.

Caetano (2015) ressalta que durante os primeiros séculos da colonização o "território alagoano"3 foi abandonado pelo governo de Pernambuco. E, mesmo com a criação da comarca das Alagoas, em 1710, fazia-se necessário que a Monarquia Portuguesa pagasse elevadas quantias ou oferecesse cargos futuros para o estabelecimento dos ouvidores, devido aos tênues rendimentos da referida comarca. Ainda segundo o autor, a criação desta deu-se, sobretudo para o "[...] controle do tabaco e o apaziguamento dos rebeldes da guerra dos mascates que pudessem ter atravessado o território [...]" (Caetano, 2015, p. 187).

Como em outras partes do país, o movimento missionário católico foi parte importante e integrou o processo de colonização

3 O termo está entre as aspas, pois na documentação primária não existe essa expressão, haja vista que o território pertencia a Pernambuco. No entanto, utilizamos para delimitar a região que hoje se conhece como estado de Alagoas. 
da região. Aos religiosos, a partir de uma pedagogia catequética, cabia a educação dos indígenas. Nesse sentido, tinham como principal função "amansar" os nativos, convertendo-os à fé católica e abrindo espaço para os conquistadores ávidos por lucros e riquezas. Conforme Queiroz (2015, p. 36), a cristianização indígena baseava-se em três pilares, quais sejam:

[...] doutrinação, moralização e sacramentalização. Primeiramente os indígenas eram obrigados a aprender de cor as palavras da doutrina cristã (credo) e as orações, mesmo sem entenderem muito bem o que diziam; era a doutrinação. Em segundo lugar, aprendiam a não cometer os atos que eram considerados pecados pelos cristãos daquela época, ou seja, deviam andar vestidos, respeitar a organização familiar monogâmica, a propriedade privada e a trabalharem como os colonos - ou para os colonos. Era a moralização. Finalmente, deviam ser preparados para receber os Sacramentos da Igreja, sobretudo o Batismo e o Matrimônio; era a sacramentalização.

Por volta do ano de 1596, um grupo de missionários franciscanos, oriundos da Custódia de Santo Antônio do Brasil, em Pernambuco, liderados pelo frei Antônio do Campo Maior, iniciou uma missão entre os índios potiguares na ribeira do rio Manguaba, região de Porto Calvo, mais especificamente em Porto de Pedras, no litoral norte das Alagoas. Em virtude da crueldade da expedição, a conversão ao catolicismo tornou-se questão de sobrevivência para os indígenas, uma vez que havia a garantia de que os índios batizados não seriam escravizados, haja vista que, introduzidos no catolicismo, seriam irmãos dos brancos portugueses. Ressaltamos que esse processo não se deu sem a resistência dos povos potiguares, que não aceitavam a religião cristã e chegavam a atacar até mesmo os indígenas cristianizados (Queiroz, 2015). 
Queiroz (2015) afirma que outra missão franciscana foi fundada em 1614 na aldeia Santo Amaro, na região do Pilar (ao centro das Alagoas), às margens do rio Paraíba. Contudo, a escassez de fontes a respeito da referida missão não nos possibilita afirmar quanto tempo durou a missão, nem tampouco quais missionários atuaram nela.

Os carmelitas, por sua vez, nas terras do atual município de Matriz do Camaragibe, litoral norte das Alagoas, por volta do ano de 1749, fundaram o Hospício de Nossa Senhora de Guadalupe, o qual contava com três frades e possuía um patrimônio que “[...] incluía seiscentas braças de terra, mais uma fazenda de gado com meia légua de terra em quadrado [...]" (Queiroz, 2015, p. 43).

Esses missionários franciscanos e carmelitas realizaram várias atividades educacionais, sobretudo a catequese e a evangelização dos nativos, com o intuito de disciplinar e moldar o comportamento dos indígenas. No entanto, ainda que as fontes sejam escassas, é também possível que eles tenham atuado no letramento desses povos.

No que diz respeito à escolarização, as primeiras notícias dão conta da instalação de uma escola jesuítica, em meados do século XVII, na fazenda Urubumirim (atual Porto Real do Colégio). Na escola, "[...] havia o ensinamento misturado à catequese, ensino que ia das primeiras letras até a recitação da jaculatória e à redação de bilhetes [...]" (Duarte, 1961, p. 28). Cabe ressaltar que, apesar da tradição do topônimo Colégio, que inclusive dá nome à cidade, na Residência Jesuítica de Urubumirim era ministrado apenas o ensino primário. Entre os padres jesuítas que atuaram nas terras alagoanas no período está o Pe. Manuel Nunes, dedicado à catequese e ao ensino primário, sendo chamado "[...] mestre de meninos ou ludi magister [...]" (Queiroz, 2015, p. 46).

Verçosa (2006) adverte quanto ao desleixo dos inacianos em relação à educação na região. Conforme o autor, a preocupação 
deles era manter uma fazenda de gado no semiárido alagoano. Vale lembrar que se iniciava na região sanfranciscana das Alagoas o movimento curraleiro com grandes latifúndios de exploração econômica da pecuária leiteira e de corte. Por não terem dado tanta atenção ao ensino, a expulsão da Companhia de Jesus por Pombal, em 1759, não teve grande repercussão na região sul de Pernambuco.

Outros focos de irradiação da cultura letrada deram-se quando da fundação dos conventos franciscanos de Santa Maria Madalena, na Vila das Alagoas, e Nossa Senhora dos Anjos, na Vila do Penedo. As notícias de uma educação institucionalizada oferecida pelos frades franciscanos nas Alagoas aparecem ainda no início século XVIII e dão conta das aulas de Gramática Latina.

Conforme Santos (2007), os primeiros mestres de Gramática Latina no convento de Penedo foram frei Nicolau do Paraíso, que lecionou de 1718 a 1726; e frei Manoel de Jesus Maria, mantendo aulas de 1755 a 1758. Já no convento das Alagoas, sede da comarca desde 1711, a autora assegura que não tenha havido prática escolar até pelo menos 1760, ainda que não possam ser ignoradas as experiências letradas vividas no interior daquela instituição religiosa, de onde saiu frei João de Santo Ângelo, que publicou em Lisboa, no ano de 1755, a Oração panegírico-fúnebre na morte do fidelissimo e augustíssimo Rei D. João V (Queiroz, 2015).

Verçosa (2006) supõe que, até o século XVIII, o ensino das primeiras letras nas Alagoas deve ter sido ministrado por preceptores e padres-mestres nas famílias mais abastadas, as quais, posteriormente, enviavam seus filhos para centros maiores, como Recife e Salvador, a fim de receberem os demais graus de instrução.

Ao que ficou evidenciado, até o final do século XVIII, não houve um impulso de grande monta no âmbito educacional nas 
partes sul da capitania de Pernambuco. A cultura intelectual na comarca das Alagoas era produzida a portas fechadas, "[...] nos claustros sombrios [...]” (Costa, 1931, p. 5) dos conventos franciscanos.

Alguma iniciativa de uma educação dirigida por não religiosos foi feita no final do século dezoito, como veremos na próxima seção.

\section{Primeiras notas sobre a educação pública nas Alagoas}

Ao iniciar esta seção, destacamos que as "primeiras notas" se referem a duas questôes: a primeira indica a ideia de início, de uma gênese da educação pública ou não dirigida por religiosos nas Alagoas; a segunda, a do ineditismo de algumas fontes ou que nunca foram analisadas no âmbito da historiografia da educação alagoana. Via de regra, as pesquisas e os trabalhos produzidos sobre a história da educação nas Alagoas partem das afirmações de Costa (1931) e Verçosa (2006) de que, no final do século XVIII e início do século XIX, existia apenas uma cadeira de Gramática Latina, na Vila das Alagoas, provida em 1798 e mantida pelo Seminário de Olinda, além de duas cadeiras de primeiras letras, uma na sede da comarca (1799) e outra em Santa Luzia do Norte $(1800)^{4}$.

Como ficou evidente na seção anterior, até a metade do século XVIII não foram encontradas notícias a respeito de uma educação não dirigida por religiosos em Alagoas. Algum apontamento

4 Não queremos aqui entrar em confronto nem tampouco desmerecer as pesquisas e contribuições desses dois grandes pesquisadores historiadores da educação alagoana. Temos consciência de que Costa (1931) e Verçosa (2006) deram-nos a conhecer a História da Educação Alagoana a partir daquilo que as condições e fontes lhes ofereciam e do que era possível ter acesso à época de suas pesquisas. 
a respeito de uma educação pública nessa comarca somente será encontrado na segunda metade do referido século. Essas parcas notas dão conta do pagamento do Subsídio Literário ${ }^{5}$ feito pelas quatro câmaras municipais das Alagoas (Vila das Alagoas, Vila de Porto Calvo, Vila do Penedo e Vila de Atalaia), no período de 1774 a 1777.

Segundo atestou Silva (2007), os mapas das cifras desse imposto demonstram com detalhes a arrecadação pelas quatro câmaras municipais das Alagoas. Entretanto, as despesas foram designadas de forma genérica, o que não possibilita a afirmação de que foram “[...] ou não gastos com educação e muito menos se havia ou não escolas e professores nas localidades listadas [...]” (p. 94). O mapa de 1777 informa que as quatro câmaras municipais da comarca das Alagoas contabilizaram 1.391 reses e 1.390 canadas (2.780 litros) ${ }^{6}$ de aguardente para fins de pagamento do referido Subsídio e teve uma despesa de 401 réis.

Nesse sentido, ainda que a fonte não deixe evidente que a despesa de 401 réis tenha sido com a instrução, tampouco indique qual ou quais professores receberam essas quantias, o mencionado gasto nos permite supor a possibilidade da existência de aulas públicas na comarca desde os idos de 1774, pelo menos. As dúvidas permanecem! Todavia, é preciso aqui fazer o exercício de compreender o não dito pela fonte, de enxergar aquilo que está oculto, ou, como afirmou Lara (2008), alargar a fonte com a capacidade de conjecturar do historiador.

5 Imposto criado pelo governo português, após a publicação do Alvará de 1772, para o financiamento da Instrução no Reino e no Ultramar. Para o caso da América portuguesa e da África, a cada 460 gramas (1 arretel - antiga medida de massa/peso - ou 1 libra) de carne verde cortada nos açougues, deveria ser pago 1 real; e a cada dois litros de aguardente da terra (1 canada), pagos 10 réis, para fins do Subsídio (Silva, 2007).

6 Reses estão relacionadas às quantidades de cabeças de gado ou outro animal de corte; e canada diz respeito a dois litros de aguardente da terra. 
A respeito da educação secundária, o requerimento de João Mendes Sanches Salgueiro, que, em 19 de outubro de 1784, solicitava à rainha, D. Maria I, o pagamento adiantado do seu ordenado anual de 300 mil réis, por motivo de sua nomeação ao cargo de professor de Gramática Latina da Vila das Alagoas. Segundo ele, serviria para pagar o seu transporte e, para isso, dava fiança, nomeando por fiador Manuel Francisco Torres, natural de Lisboa e assistente em Arroios (Brasil, Cx. 3, D. 231).

Natural da Vila de Amieira, em Portugal, Salgueiro é o primeiro nome de professor público localizado até agora nas Alagoas. Ainda sobre o professor, vale salientar que, após acusação de D. Luiza Botelho, foi processado pelo Santo Ofício, em 31 de agosto de 1796. Sobre ele recaía a acusação de fazer proposições heréticas, pois, na casa da Condessa de São Miguel, D. Anna, onde ele se hospedava, “[...] mostrava desprezo das imagens de Nossa Senhora, dizia que não havia Inferno; fazendo zombaria dos actos da Religião [...]" (ANTT, 1792). Conforme Fonseca (2009, p. 98.)

Vários de seus ex-alunos foram interrogados, dizendo que o professor comia carne em dias proibidos, que condenava as reverências às imagens sagradas, que faltava com o respeito ao Santíssimo Sacramento, e que desaparecera da Vila supostamente por ter cometido um homicídio. O comissário encarregado chegou, afinal, à conclusão de que não procediam as acusações, embora reconhecesse que o professor não levava uma vida exemplar, sobretudo quanto à prática da religião. O maior prejuízo seria o mau exemplo que ele dava aos seus discípulos, quando deveria, por suas atribuições profissionais, estimular a difusão da doutrina no processo de formação do súdito cristão. 
Observa-se que a conduta do professor não condizia com o padrão estabelecido à época, sobretudo no que diz respeito à obediência, à moral e à doutrina católica, por ser considerado pouco respeitoso com as coisas da religião. $\mathrm{O}$ fato de ser professor agravava ainda mais a situação, uma vez que Salgueiro estaria disseminando a inobservância às leis e às práticas da fé e da religião, bem como porque a formação moral dos alunos dependia do bom exemplo que o professor deveria dar-lhes, o que seu comportamento pouco adequado não permitia.

Outro professor que figurou a aula de Gramática Latina da Vila das Alagoas, no final do Setecentos, foi José Fernandes Gama. Este, que posteriormente foi transferido para a cadeira de Olinda e depois para a do bairro Boa Vista, em Recife, envolveu-se juntamente com o professor José Leitão de Almeida em uma grande querela com o Bispo de Olinda e Diretor Geral de Estudos, D. José da Cunha Azeredo Coutinho. Entre outras acusações, os professores denunciavam o desvio do Subsídio Literário por parte do prelado (Brasil, Cx. 213, D. 14.457).

Em resposta às acusações e procurando provas para incriminá-lo, Coutinho descobriu que, quando professor na Vila das Alagoas, Gama deu provas de desprezo para com a religião e imoralidades, "[...] dificultando o acesso de seus alunos aos eventos religiosos que ocorriam na vila durante os horários de suas aulas [...]" (Silva, 2007, pp. 151-2), conforme atestou o vigário geral forâneo das Alagoas, padre Agostinho Rabelo de Almeida, que era Comissário do Santo Ofício em Alagoas. Além desta, pesavam sobre o professor as denúncias de ter traduzido a Arte de amar, de Ovídio, bem como o assédio, sedução, rapto e abandono da jovem $\mathrm{D}$. Benta Maria da Conceição, entre os anos de 1796 e 1797. Segundo Silva (2007, p. 152),

O pai da menina tratou de enclausurá-la no Recolhimento de Nossa Senhora da Conceição de Olinda, para livrá-la do 
assédio do professor. A clausura não pôde contê-lo porque ele arranjou um jeito de continuar a se comunicar, por cartas, com a moça, até conseguir fugir com ela e ir para o Recife. Naqueles tempos que corriam, ele já havia feito filhos com ela, já a tinha prostituído e abandonado e já estava com uma outra.

Contudo, apesar dessas acusações, Gama saiu ileso, continuou a exercer o magistério e passou a receber uma pensão de $200 \mathrm{mil}$ réis anuais, paga com os valores do Subsídio Literário. Posteriormente, viajou para Lisboa, onde atuou como procurador de uma série de “[...] pessoas importantes [...]" da capitania de Pernambuco (Silva, 2007, p. 153).

Insere-se aqui um paradoxo entre os preceitos e a orientação religiosa do mundo luso-brasileiro, fortemente marcado pela influência da Igreja Católica e pela tentativa de uma renovação a partir dos ideais do Iluminismo. Desta feita, no cotidiano, os professores deveriam ser para seus discípulos o exemplo de uma conduta moral, civil e religiosa, antes que mestres de uma determinada cadeira.

Salientamos que o desenvolvimento da educação não dirigida por religiosos no último quartel do século XVIII não foi um fenômeno específico das partes sul, mas algo comum na capitania de Pernambuco. Conforme Pinheiro (2002), a referência de escolarização pública na Paraíba, então pertencente à citada capitania, remonta ao ano de 1783, quando a cadeira de Latim, criada em 1766, foi provida pelo professor João Adolfo.

Pelo ofício da Junta Governativa da Capitania de Pernambuco ao secretário de estado da Marinha e Ultramar, Rodrigo de Sousa Coutinho, de 1799, bem como pelo ofício do bispo de Pernambuco, D. José da Cunha Azeredo Coutinho, à Junta Governativa da Capitania de Pernambuco, de 27 de setembro de 1800, é possível 
identificar que a comarca das Alagoas possuía, no ano de 1795 , quatro aulas de primeiras letras e duas de Gramática Latina.

As aulas primárias estavam localizadas na Vila das Alagoas, regida pelo professor José Vitorino da Rocha; no termo de Santa Luzia da Lagoa do Norte, regida por Bartholomeu Antonio de Sousa; na freguesia de Porto Calvo, do lente Gonçalo Correia da Costa; e na Vila de Penedo, regida por Miguel Barreto de Almeida. As duas aulas de Gramática Latina eram, em Alagoas, cadeira pertencente a José Pereira Rodrigues de Alcântara, e em Penedo, do catedrático padre Gabriel José Pereira de Sampaio. Os professores das primeiras letras percebiam; $80 \$ 000$ réis, os de Santa Luzia e Porto Calvo; $100 \$ 000$ réis, o de Penedo; e 120\$000 réis, o das Alagoas. Já os de Gramática recebiam: $300 \$ 000$ réis, os de Alagoas, além de uma gratificação de 350\$000; $240 \$ 000$ réis, os de Penedo (Brasil, Cx. 207, D. 14.204 e Cx. 219, D. 14.849). Assim, findo o Setecentos, a comarca possuía quatro professores de primeiras letras e dois de Latim.

Salientamos que o padre Gabriel José Pereira de Sampaio, além de professor de Latinidade da Vila de Penedo, desde 1792, foi um dos últimos funcionários inquisitoriais a atuar na comarca das Alagoas. Natural da Bahia, o sacerdote recebeu a comenda de Comissário do Santo Ofício, em 1808, tornando-se apto a proteger a sociedade contra os desvios da fé católica (Debates de História Regional, 1992). Conforme Machado (2016), padre Gabriel era membro dos quadros mais respeitáveis da Irmandade de São Gonçalo Garcia dos Homens Pardos, da Ordem Terceira e da Irmandade do Santíssimo Sacramento. E, mesmo antes de receber sua habilitação como Comissário do Santo Ofício, o padre denunciou, em 1793, Manoel Gomes Ribeiro e José Gomes Ribeiro, recifenses, irmãos, comerciantes e Familiares do Santo Ofício, de viver cada um em concubinato. A denúncia do padre foi sobre "[...] o horrivel exemplo, dé q na Rua mais publica desta $V^{a}$ [Vila], e junto aos Paços da Camara, em 'q pus Classe vivem 
escandalozissimam ${ }^{\text {et }}$ dous mizeraveis homens concubinados publicam ${ }^{\text {e }}$ de sorte, 'q me faz horror prezenciarem os meus alunos" (ANTT, 1793).

Em 1807, o padre Gabriel Sampaio solicitou ainda à realeza portuguesa a mercê do hábito da Ordem de Cristo, honraria nobilitante da ordem religioso-militar portuguesa sob o controle da Coroa desde finais do século XV. Além disso, suplicava o dobro do ordenado de professor régio de Latinidade e a sucessão ao pároco da Vila do Penedo, António José de Matos, tudo em remuneração dos seus serviços e ao donativo que fez à Fazenda Real como juiz da Irmandade de São Gonçalo Garcia (Brasil, Cx. 6, D. 465). Fica subtendido que o suplicante conhecia bem a dinâmica economia de mercês da Coroa Portuguesa, a qual, para recompensar os serviços dos seus súditos, concedia-lhes várias benesses e privilégios, acompanhados de significativos rendimentos monetários ${ }^{7}$.

Entre as aulas de primeiras letras que existiam na comarca, a da Vila de Penedo era regida, há 15 anos, pelo professor Miguel Barreto de Almeida, que, em 30 de setembro de 1806, solicitou ao príncipe regente, D. João, acrescentamento de soldo para vestuário, alimentos, habitação para si e seus alunos, além de dispensa de cinco anos de serviço para ter sua jubilação. Conforme mapa apresentado anexo ao pedido, Almeida afirma ter ensinado 88 alunos, em 1806 (Brasil, Cx. 6, D. 440).

Em 1798, o governador da capitania de Pernambuco, D. Tomas José de Melo, comunicou aos professores de Gramática Latina que, por Alvará datado de 4 de setembro de 1797, expedido pelo secretário de estado da Marinha e Ultramar, D. Rodrigo de Sousa Coutinho, eles podem utilizar em suas aulas os compêndios

7 A respeito dessa temática, cf. Olival, 2001. 
de suas conveniências e que julgam mais úteis e fácies aos programas de seus discípulos (Brasil,Cx. 201, D. 13.754).

Essa determinação de utilização dos compêndios mais simples e mais fáceis está balizada nas ideias das reformas pombalinas, que considerava a pedagogia jesuítica muito fastidiosa, ao que o Alvará classificava como método antigo. Para Pombal, a aprendizagem deveria reduzir-se aos termos simples, claros e de maior facilidade, como já se praticava nas demais nações europeias. Nesse sentido, a reforma fazia o elogio do ensino rápido, ainda que mantivesse as cadeiras ministradas nos colégios jesuítas (Ramos do Ó, 2009). Salientamos ainda que o conceito de curso rápido foi de grande valia para o sucesso dos colégios particulares, haja vista que o ensino liceal ficou associado a algo enfadonho e maçante pela necessidade do aluno concluir todos os anos do curso para, posteriormente, prestar os exames para as faculdades.

Em 1815, a comarca passou a contar com mais duas vilas, Maceió e Porto Pedras. Tomando emprestado o nome e a padroeira do engenho Massayó, Nossa Senhora dos Prazeres, a Vila de Maceió foi desmembrada da das Alagoas a 05 de dezembro, tendo como espaço territorial a faixa que vai desde a Barra das Alagoas até o Rio Santo Antônio Grande e Mundaú. Desde o século XVII, Maceió já se destacava como sendo um polo de escoamento do açúcar produzido nos engenhos locais, madeiras e algodão, pelo porto natural de Jaraguá. Porto de Pedras, por sua vez, foi desmembrada da Vila de Porto Calvo, e abrangia o território que ia do Rio Manguaba até o Rio Santo Antônio Grande. Segundo alvará de criação, ambas as vilas, deveriam erguer o Pelourinho, a Casa de Câmara, a Cadeia e mais "oficinas necessárias".

Por sua elevação à vila, Maceió ganhou uma aula de instrução primária. Desta feita, em 1818, foi nomeado para professor régio de primeiras letras o padre Francisco do Rego Baldaia, com o or- 
denado de $80 \$ 000$ réis pagos por quartéis ${ }^{8}$, sendo depois substituído por Francisco Pereira Guedes (Costa, 2001). Em mapa datado de $1 .^{\circ}$ de abril de 1819, Baldaia afirma ter ensinado 66 alunos, todos do sexo masculino, tendo entre 5 e 13 anos de idade. É possível também verificar que a maioria, cerca de 44, estava em lições de matemática, como "juros, repartir, sómar, multiplicar e taboada", os outros, nas lições de língua portuguesa: "ler, nomes e abc" (Alagoas, cx. 1799). Entre os alunos listados no mapa de Baldaia, encontra-se Francisco Elias Pereira, que foi professor de Geometria em Maceió, de 1844 a 1849, bem como do Lyceu Alagoano, fundado em 1849.

Padre, jornalista e professor régio de primeiras letras, Baldaia, segundo Queiroz (1996), foi ainda político e agitador popular temível, famoso por sua exagerada lusofobia. Na vice-presidência da Sociedade Patriótica de Maceió, o professor ajudou a fundar o periódico Iris Alagoense, em 1831. Primeiro jornal da província, o Íris Alagoense, editado pelo francês Adolfo Emílio de Bois Garin e redigido pelo padre Afonso de Albuquerque e pelo advogado Félix José de Melo Silva, é considerado o ponto inicial do desenvolvimento político e da formação cultural do povo alagoano (Costa, 2001). Dizia o Íris, em seu frontispício: “A opinião pública acometendo os reis sobre os tronos há de contê-los nos limites de uma autoridade legal"'. A partir de 1832, o periódico passou a denominar-se $O$ Federalista Alagoense, sendo que, em 1833, Baldaia assumiu a direção do jornal.

Conforme Vasconcellos (2016), a Vila das Alagoas ganhou uma aula de Geometria, em 1816. Para essa, cadeira foi nomeado professor Joaquim do Amor Divino, o frei Caneca. Aos 37 anos

8 Um quartel indica um período de quatro meses. Assim, os professores recebiam a cada três meses, regularidade comum à época.

9 Não é objeto deste trabalho a discussão sobre o que era opinião pública para o período ou o que seria entendido por tal expressão. 
e já tendo ensinado as cadeiras de "[...] filosofia racional e moral, e ainda de retórica, nos ambientes que frequentava desde o início do século: o convento do Carmo, a biblioteca dos padres oratorianos, ambos no Recife, e ainda o recém-inaugurado seminário de Olinda [...]" (Vasconcellos, 2016, p. 99), Caneca ficou pouco tempo na comarca, seu desejo era assumir posto semelhante em lugar com maior prestígio, porém o espírito político e revolucionário na Insurreição Pernambucana de 1817 impediu este propósito.

Após a insurreição de 1817, a comarca ao sul da capitania de Pernambuco adquiriu autonomia política, passando a denominar-se capitania das Alagoas, com sede na Vila das Alagoas ${ }^{10}$. Com a criação da capitania, foram criadas mais duas cadeiras, Filosofia e Geometria, na capital.

\section{Considerações finais}

Na busca por apreender a história da educação em Alagoas, este texto ofereceu uma narrativa a respeito da educação ofertada por não religiosos na região. A localização e o trato com fontes primárias, até então desconhecidas no âmbito da historiografia da educação alagoana, trouxe à tona informações, fatos e dados que oferecem uma nova interpretação para o que pode ser considerado a gênese de uma educação pública nas Alagoas, ou pelo menos de uma educação não dirigida por religiosos, como preferimos afirmar.

10 Não quero aqui entrar na discussão interminável que existe entre os autores alagoanos a respeito desse fato, se foi uma forma de punição a Pernambuco na tentativa de enfraquecer a capitania, devido à Revolução Pernambucana de 1817, como defende Moreno Brandão (1909), ou se a comarca já possuía as condições necessárias para emancipar-se, como defende Jaime de Altavila (1988), ou mesmo os dois motivos, como defende Verçosa (2006). 
Essas informações dão conta de que, desde pelo menos 1777 , já havia gastos com educação nas Alagoas, fato que possibilita a afirmação da existência de uma educação pública desde aqueles idos. Outro dado importante diz respeito ao nome e à atuação do professor de Gramática Latina, João Mendes Sanches Salgueiro, primeiro nome de professor público das Alagoas localizado até então.

Por fim, salientamos que as contribuições iniciais que o texto traz para a historiografia da educação alagoana não se esgotam aqui. Não há de nossa parte qualquer pretensão de consumir o enorme leque de interpretações e possibilidades que as fontes documentais podem trazer em futuras pesquisas. Neste texto, entre outras coisas, buscamos apontar caminhos e despertar o interesse daqueles que pretendem enveredar pelos difíceis rumos da investigação histórica em educação.

\section{Referências}

ALAGOAS. Arquivo Público de Alagoas. "Mapa dos alunos que frequentavam as aulas régias das primeiras letras com o professor Padre Francisco do Rego Baldaia da Vila Maceió, 1819”. Cx. 1799.

ALTAVILA, Jaime. História da civilização das Alagoas. Maceió: EDUFAL, 1988.

ANTT/Tribunal do Santo Oficio/Inquisição de Lisboa. Processo de João Mendes Sanches Salgueiro, 1792.

. Cx. 1.643, documentação dispersa 1620-04-22/1820-0912. Processo 17.462. Denúncia contra José Gomes Ribeiro e contra Manuel Gomes Ribeiro, 1793.

AZEVEDO, Fernando de. A transmissão da cultura. São Paulo: Melhoramentos, 1976. 
BACELLAR, Carlos. "Fontes documentais: uso e mau uso dos arquivos”. In PINSKI, Carla Bassanezi. Fontes históricas. São Paulo: Contexto, 2014.

BLOCH, Marc. Apologia da história - ou o ofício do historiador. Rio de Janeiro: Jorge Zarar, 2001.

BRANDÃO, Moreno. História de Alagoas. Penedo: Artes Graphicas Typ. e Pautação, 1909.

BRASIL. MINC. Alagoas. Documentação do Projeto Resgate de Documentação Histórica Barão do Rio Branco. Arquivo Histórico Ultramarino - Cx. 6, D. 465.

. MINC. Pernambuco. Documentação do Projeto Resgate de Documentação Histórica Barão do Rio Branco. Arquivo Histórico Ultramarino - Cx. 3, D. 231.

. MINC. Pernambuco. Documentação do Projeto Resgate de Documentação Histórica Barão do Rio Branco. Arquivo Histórico Ultramarino - Cx. 6, D. 440.

. MINC. Pernambuco. Documentação do Projeto Resgate de Documentação Histórica Barão do Rio Branco. Arquivo Histórico Ultramarino - Cx. 201, D. 13754.

. MINC. Pernambuco. Documentação do Projeto Resgate de Documentação Histórica Barão do Rio Branco. Arquivo Histórico Ultramarino - Cx. 207, D. 14154;

. MINC. Pernambuco. Documentação do Projeto Resgate de Documentação Histórica Barão do Rio Branco. Arquivo Histórico Ultramarino - Cx. 213, D.14457.

. MINC. Pernambuco. Documentação do Projeto Resgate de Documentação Histórica Barão do Rio Branco. Arquivo Histórico Ultramarino - Cx. 219, D. 14849. 
CAETANO, Antonio Filipe Pereira. "A comarca das Alagoas: justiça, trajetórias e conflitos (1712-1817)”. In CAETANO, Antonio Filipe Pereira (org.). Das partes sul à comarca das Alagoas, capitania de Pernambuco: ensaios sobre justiça, economia, poder e defesa (século XVII-XVIII). Maceió: Viva Editora, 2015.

CARDOSO, Ciro Flamarion e VAINFAS, Ronaldo. "História e análise de texto". In (org.). Dominios da História: ensaios de teoria e metodologia. Rio de Janeiro: Campus, 1997.

CERTEAU, Michel de. "A operação historiográfica”. A escrita da história. Rio de Janeiro: Forense Universitária, 1982, pp. 65119.

COSTA, Craveiro. Instrução Pública e instituições culturais de Alagoas. Monografia Escrita por solicitação do Ministério da Educação e Saúde Pública. Imprensa Oficial: Maceió, 1931.

. Maceió. Maceió: Edições Catavento, 2001.

Debates de História Regional, Revista do Departamento de História da Universidade Federal de Alagoas, Maceió, 1992.

DIÉGUES JÚNIOR, Manuel. O bangüê nas alagoas: traços da influência do sistema econômico do engenho de açúcar na vida e na cultura regional. 3 ed. Maceió: EDUFAL, 2006.

DUARTE, Abelardo. História do Liceu Alagoano. Maceió: Departamento Estadual de Cultura, 1961.

FONSECA, Thaís Nivia de Lima e. Letras, ofícios e bons costumes: civilidade, ordem e sociabilidade na América portuguesa. Belo Horizonte: Autêntica, 2009.

LARA, Sílvia H. "Os documentos textuais e as fontes do conhecimento histórico". Anos 90, Revista do Programa de Pós-Gra- 
duação da Universidade Federal do Rio Grande do Sul, v.15, n. 28, pp. 17-39, dez. 2008.

MACHADO, Alex Rolim. "Viver a vida e fiscalizar a dos outros: os agentes da Inquisição nas câmaras, confrarias e milícias em Alagoas colonial, 1790-1820”. Questionis Documenta, Revista do Arquivo da Cúria Metropolitana de Maceió, ano I, n. 1, 2016, pp. 21-45.

OLIVAL, Fernanda. As ordens militares e o Estado moderno: honra, mercê e venalidade em Portugal (1641-1789). Lisboa: Estar, 2001.

PINHEIRO, Antonio Carlos Ferreira. Da era das cadeiras avulsas à era dos grupos escolares na Paraíba. Campinas: Autores Associados, 2002.

QUEIROZ, Álvaro. Notas de história da Igreja nas Alagoas. Maceió: EDUFAL, 2015.

RAMOS DO Ó, Jorge. Ensino liceal (1836-1975). Lisboa: Ministério da Educação, 2009.

REVISTA DO INSTITUTO HISTÓRICO E GEOGRÁFICO DE ALAGOAS. "Registro da Provisão e Alvará porque se mandou crear a vila de Massaió”. V. II, n. 15, pp. 150-5, dez. 1882.

SANTOS, Mônica Costa. Missionários de letras e virtudes: a pedagogia moral dos franciscanos em Alagoas nos séculos XVIII e XIX (dissertação). Universidade Federal de Alagoas, 2007.

SILVA, Adriana Maria Paulo da. Processos de construção das práticas de escolarização em Pernambuco, em fins do século XVIII e primeira metade do século XIX. Recife: Editora Universitária da UFPE, 2007.

VASCONCELLOS, Pedro Lima. "Cenas do catolicismo 'crioulo' na alvorada do século XIX”. Questionis Documenta, Revista 
do Arquivo da Cúria Metropolitana de Maceió, ano I, n. 1, pp. 98-113, 2016.

VERÇOSA, Elcio de Gusmão. Cultura e educação nas Alagoas: história, histórias. 4 ed. Maceió: EDUFAL, 2006. 